\title{
Effect of packaging on the shelf life of tender palmyra (Borassus flabellifer) fruit endosperm
}

\author{
Dawn C.P. Ambrose \\ Central Institute of Agricultural Engineering, Regional Centre, Coimbatore-7, Tamil Nadu, \\ India \\ E-mail: dawncp@yahoo.com
}

\section{Article Info}

DOI:10.31018/jans.v10i2.1770 Received: February 8, 2018

Revised: March 26, 2018

Accepted: May 5, 2018

\section{How to Cite}

Ambrose, D.C.P. (2018).

Effect of Packaging on the shelf life of tender palmyra (Borassus flabellifer) fruit endosperm. Journal of Applied and Natural Science, 10 (2): 705 - 709 ated $\left(5 \pm 1^{\circ} \mathrm{C}\right)$ conditions. The endosperm was packed in polypropylene bags of 40 conditions. The endosperm was packed in polypropylene bags of 40 High Molecular density (HM) polyethylene bags of 40 micron thickness. The packed samples were kept for storage under ambient and refrigerated conditions. They were evaluated for the changes in weight loss, TSS and also firmness, colour and odour by subjective evaluation at periodic interval during storage. The weight loss was minimum for the sample packed in $\mathbf{4 5 0}$ micron Low Density Polyethylene bag under refrigerated storage. Sensory scores revealed that the overall acceptability(5.0) of palmyra endosperm packed in 450 micron thickness Low Density Poly Ethylene was highest at the end of storage under ambient condition. Similarly, highest overall acceptability (4.0) was observed in High Molecular density polyethylene bag of 40 micron thickness at refrigerated storage. Under normal conditions, palmyra endosperm is prone to spoilage within few hours due to oxidation and fermentation. The results of the study revealed that the shelf life of palmyra endosperm could be extended up to two days under ambient condition, when packed in Low Density Poly Ethylene bag of 450 micron thickness, whereas under refrigerated condition, shelf life could be up to eight days, when packed in high molecular density polyethylene bags of 40 micron thickness.

Keywords: packaging, quality, shelf life, storage, tender palmyra endosperm

\section{INTRODUCTION}

Palmyra is a tall growing tree which belongs to the family, Arecaceae. It is botanically known as Borassus flabellifer $L$. having a genus of six species of fan palms. It is also known as sugar palm. It is found in abundance mainly in Asian countries such as India, Thailand, Bangladesh, Myanmar, Sri Lanka, Malaysia, etc. having multipurpose utility (Sankaralingam et al.,1999). In India, it is abundantly found in the states of Tamil Nadu and Andhra Pradesh and its distribution extents in the states of Kerala, Karnataka, Goa, Maharashtra, Gujarat, Orissa and southern part of Bihar. Based on the multiple uses of the tree, it is also called as "Kalpaka Vriksha" and is the state tree of Tamil Nadu (Anonymous, 1999).

The female tree yields to economic edible products viz., the endosperm, pulp and the tuber (Vijayakumari et al., 2015). The tender fruit endo- sperm and the palm nectar is a summer delicacy consumed in the Southern and Eastern parts of India. When the tender fruit is cut open at the top, three sockets are found inside and these contain the kernel which is soft as jelly, and translucent like ice, and is accompanied by a watery sweetish liquid. It is also called as ice apple named by the British since it resembles ice. The fruit is a much sought after delicacy during summer months. Ice apple acts as a coolant for the parching throat on a hot summer day and is relished during the summer months. It provides a perfect balance of minerals and sugar for the body during the summer season. The fruit, which is available in abundance during the hot season, is rich in B vitamins, iron and calcium. It is used as a remedy for ulcer, urinary infection and heat rashes which mainly occur during summer months (Ramya, 2014).

The endosperm of tender palmyra fruit has the outer fibrous covering containing the sugary gelat- 
inous pod. The outer skin of the jelly is yellowish brown in colour and is much prone to oxidation and the taste and flavor of the endosperm tends to change due to this. The whole tender palmyra fruit suffers from weight loss, shrinkage, etc. after 2 weeks of storage. Moreover the ice apple or palmyra endosperm is sold by the road side vendors wherein the hygienic packaging is greatly limited.

Packing perishable products in correct packaging films can extend it's shelf life. Polyethylene packaging has been found to extend the keeping quality of fruits and vegetables (Elisa et al., 2012). These packages tend to alter the gaseous composition due to the respiration of the stored samples. Hence to have a better quality of the packed product, selection of the right type of packaging film is an important factor to be considered. Palmyra endosperm is consumed immediately after extraction from the fruit since it is more prone to oxidation and fermentation (Catherine Reddy, 2013) when kept in open condition and thereby subjected to spoilage within few hours. Information on packaging palmyra endosperm is limited and this study aimed to test the effect of packaging on the shelf life of tender palmyra endosperm at different storage conditions.

\section{MATERIALS AND METHODS}

Raw material: Fresh tender palmyra fruits were procured from a local vendor at Coimbatore, Tamil Nadu. The fruits were cut opened with a cutting knife and the endosperm was scooped out from the fruit. In each package three fresh endosperm weighing around $250 \mathrm{gm}$ each was taken.

Packaging treatments: Packaging films of different thickness viz., polypropylene (PP) 40 micron, polypropylene (PP) 80 micron, low density polyethylene (LDPE) 150 micron, low density polyeth- ylene (LDPE) 450 micron and high molecular density (HM) polyethylene 40 micron for retail packaging were selected based on the availability in the local market. The size of the bags was $200 \times 150$ $\mathrm{mm}$. The samples were packed in the retail packaging and kept under storage at ambient $\left(32 \pm 2^{\circ} \mathrm{C}\right)$ and refrigerated conditions $\left(5 \pm 1^{\circ} \mathrm{C}\right)$. The samples were not subjected to any postharvest chemical treatments. The samples were kept for storage till deterioration of the sample was not noticed.

Periodic evaluation of the samples: The stored samples were periodically analysed for their physio sensory quality on daily basis.

Physiological weight loss: The physiological weight loss of the packed tender palmyra endosperm was determined based on the difference in initial weight and loss in weight recorded during periodic evaluation of sample during storage (Kudachikar, 2011).

Total soluble solids: TSS was measured periodically using hand held refractometer $\left(0-32^{\circ}\right.$ Brix; ERMA, Japan) (Kishore et al., 2011).

Sensory quality: Sensory analysis is the ultimate tool for evaluation of quality and quality changes (Martens and Martens, 2001). The sensory quality viz., colour, odour, taste, firmness and overall acceptability of the samples were evaluated on a 5 point hedonic scale daily during storage.

Statistical analysis: The experimental data were statistically analysed by Factorial Design with three replications using AGRES software.

\section{RESULTS AND DISCUSSION}

Physiological weight loss under ambient storage: The changes in weight of the samples compared to the initial weight expressed as weight loss during storage at ambient condition is presented in Fig. 1. There was a gradual increase in the physiological weight loss of samples with the

Table 1. TSS of palmyra endosperm during storage.

\begin{tabular}{|c|c|c|c|c|c|c|c|c|c|c|}
\hline \multirow{3}{*}{$\begin{array}{l}\text { Packaging } \\
\text { Treatment }\end{array}$} & \multicolumn{2}{|c|}{ Ambient } & \multicolumn{8}{|c|}{ Refrigerated } \\
\hline & \multicolumn{2}{|c|}{ Days of storage } & \multicolumn{8}{|c|}{ Days of storage } \\
\hline & 1 & 2 & 1 & 2 & 3 & 4 & 5 & 6 & 7 & 8 \\
\hline PP-40 & 7.5 & 7.5 & 8 & 8 & 8 & 8 & 8 & 8 & 8 & 8 \\
\hline PP-80 & 7.5 & 7.5 & 8 & 8 & 8 & 8 & 8 & 8 & 8 & 8 \\
\hline LDPE-150 & 8 & 8 & 8 & 8 & 8 & 8 & 8 & 8 & 8 & 8 \\
\hline LDPE-450 & 8 & 8 & 8 & 8 & 8 & 8 & 8 & 8 & 8 & 8 \\
\hline HM-40 & 8 & 8 & 8 & 8 & 8 & 8 & 8 & 8 & 8 & 8 \\
\hline
\end{tabular}

Table 2. Sensory attributes of samples under ambient storage.

\begin{tabular}{|c|c|c|c|c|c|c|c|c|c|c|}
\hline \multirow[t]{3}{*}{ Treatment } & \multicolumn{2}{|c|}{ Colour } & \multicolumn{2}{|c|}{ Odour } & \multicolumn{2}{|c|}{ Taste } & \multicolumn{2}{|c|}{ Firmness } & \multicolumn{2}{|c|}{ Overall acceptability } \\
\hline & & & & & & \multicolumn{3}{|c|}{ Days of storage } & & \\
\hline & 1 & 2 & 1 & 2 & 1 & 2 & 1 & 2 & 1 & 2 \\
\hline PP-40 & $5^{\mathrm{a}}$ & $3^{\mathrm{c}}$ & $5^{a}$ & $3^{c}$ & $4^{b}$ & $4^{\mathrm{b}}$ & $5^{a}$ & $3^{\mathrm{c}}$ & $5^{a}$ & $3^{\mathrm{c}}$ \\
\hline PP-80 & $5^{a}$ & $3^{c}$ & $5^{a}$ & $4^{b}$ & $4^{b}$ & $4^{\mathrm{b}}$ & $5^{a}$ & $4^{b}$ & $5^{a}$ & $4^{b}$ \\
\hline LDPE-150 & $5^{a}$ & $3^{c}$ & $5^{a}$ & $4^{b}$ & $4^{b}$ & $4^{b}$ & $5^{a}$ & $4^{b}$ & $5^{a}$ & $4^{b}$ \\
\hline LDPE-450 & $5^{a}$ & $4^{b}$ & $5^{a}$ & $4^{b}$ & $5^{a}$ & $4^{b}$ & $5^{a}$ & $5^{a}$ & $5^{a}$ & $5^{a}$ \\
\hline $\mathrm{HM}-40$ & $5^{a}$ & $3^{c}$ & $5^{a}$ & $4^{b}$ & $5^{a}$ & $4^{b}$ & $5^{a}$ & $4^{b}$ & $5^{a}$ & $4^{b}$ \\
\hline
\end{tabular}

Hedonic scale for colour, odour, taste, firmness and overall acceptability: $1=$ poor; $2=$ average; $3=$ good; $4=$ very good; $5=$ excellent, $a, b, c-$ Within columns, the same letter denotes, they are not significantly different $P<0.05$ 


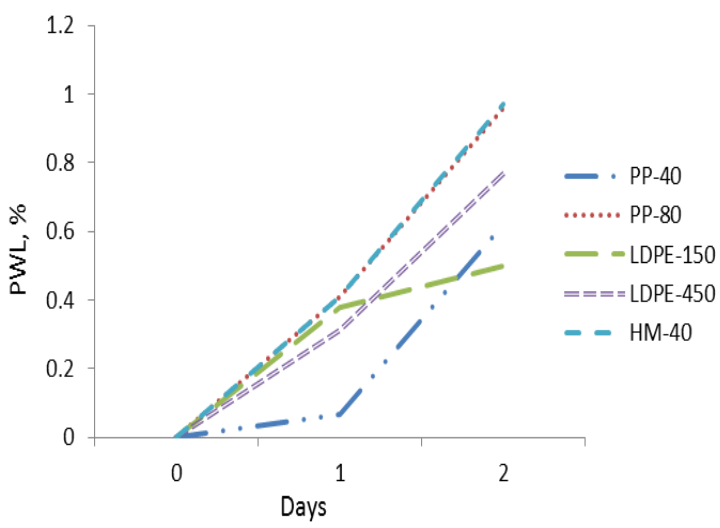

Fig. 1. Effect of packaging materials on the physiological weight loss of Palmyra endosperm at ambient storage.

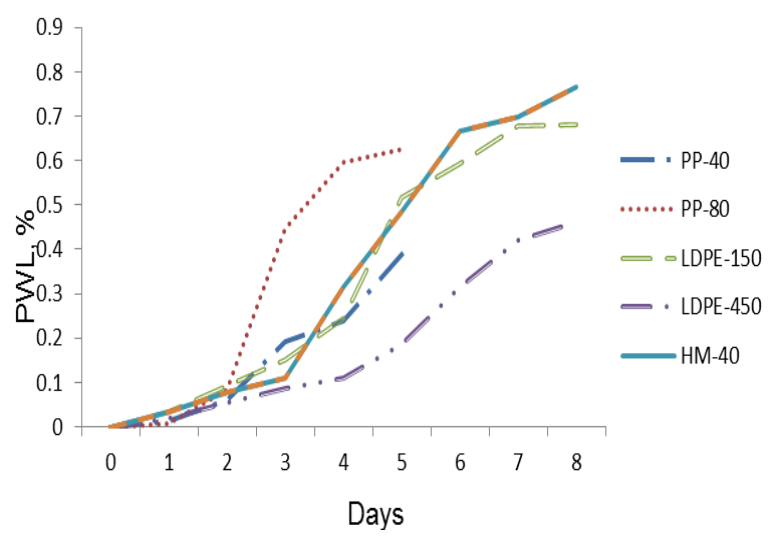

Fig. 2. The effect of packaging materials on the physiological weight loss of Palmyra endosperm at refrigerated storage.

advancement of storage period.

The lowest weight loss $(0.068 \%)$ was seen in polypropylene 40 micron thickness film followed by LDPE 450 micron at day one of the storage period, however, the weight loss was found to be lesser $(0.5 \%)$ in the case of sample packed in LDPE 150 micron film thanthe samples packed in other films at the end of storage under ambient condition. Similar result was observed for rambutan fruits showing lowest weight loss when packed in LDPE bags (Elisa et al., 2012).

Physiological weight loss under refrigerated storage: The physiological weight loss under refrigerated storage is presented in Fig. 2. Weight loss during storage is attributed to loss of moisture and reserve food materials by evapo-transpiration and respiration, respectively (Siddiqui, et al., 1999). Under refrigerated storage condition, it could be seen that the weight loss occurred in a slow phase (Fig.2).

Similar results have been observed in curry leaf packed in different packaging materials (Dawn et al., 2015). From Fig. 2, it was seen that the physiological weight loss was under steady increase for polypropylene films. The experiment was discon- 
tinued after 5 days due to moisture condensation inside the polypropylene packages. LDPE 450 film encountered minimum weight loss $(0.46 \%)$ under refrigerated condition.

Changes in TSS during storage: The total soluble solids of palmyra endosperm was measured and presented in Table 1 during storage.

There were no changes in TSS observed during storage, except for a slight drop for the samples packed in polypropylene bags of 40 and $80 \mathrm{mi}-$ cron thickness at ambient condition. In the case of refrigerated storage, there were no changes in TSS observed throughout the storage period. The low temperature may prevent the hydrolysis of polysaccharides (Bhardwaj and Nandal, 2014). Similar observation was noted for onion at low temperature storage wherein there was no changes in TSS content up to 20 days when kept in polyethylene pouches (Sohany et al., 2016).

Quality changes observed in sensory attributes: The acceptance of the stored samples at ambient and refrigerated conditions were analysed based on the sensory scores ranging from 5 to 1 (Excellent to poor) and presented in tables 2 and 3 . From table 2, it could be seen that based on the colour score (4), LDPE-450 was better compared to other samples at the end of storage. The colour rating was done for the whole endosperm with the outer covering. The endosperm of tender palmyra fruit has the outer covering which is more subjected to browning and hence the samples could not retain their original colour at the outer skin whereas, the colour of the inside jelly remained the same, as white translucent. Based on the rating for odour, sample packed in polypropylene 40 micron showed the least value (3) whereas samples packed in other packaging films resulted in the same score (4). The scores on taste of the samples remained unaltered (5) for LDPE-450 and HM-40 on the first day. However on the second day, there was no significant difference among the packaging treatments.

The texture of the endosperm as described by it's firmness was found to highest (5) in the case of sample packed in LDPE-450 film. There was no significant difference among the samples except for PP-40 film (3) at the end of storage. The overall acceptability of the samples, revealed that the LDPE-450 film had the highest score (5) compared to other packaging materials at the end of storage. Rambutans packed in LDPE film showed a higher overall acceptability (3.3) based on the sensory scores (Elisa et al., 2012).

From table 3 , it could be seen that the colour scores of all the samples got reduced to 3 after three days except for the sample (4) stored in HM40 film. The scores on the odour of the samples reduced to 3 after four days of storage. All the samples encountered a decrease in firmness after 4 days, whereas, the sample packed in $\mathrm{HM}-40$ film retained their texture till the end of storage period. The overall acceptability $\mathrm{HM}-40$ was the highest (4) compared to the other polymeric films at the end of storage. This may be due to the high barrier property of the film to moisture and atmosphere resulting in better retention of the product's quality.

Samples packed in polypropylene films exhibited good acceptability only up to four days (table 3 ) and thereby resulted in reduced scores on the quality attributes. This may be due to the reason of increase in $\mathrm{CO}_{2}$ concentration inside the package, resulting in quick deterioration of the quality. Increase in $\mathrm{CO}_{2}$ and decrease in $\mathrm{O}_{2}$ was observed for Korean red leaf lettuce when packed in non perforated polypropylene films (Lee and Chandra, 2018).

\section{Conclusion}

Tender palmyra endosperm is a much sought after summer delicacy which is being immediately consumed. The keeping quality of fresh endosperm is limited and gets spoiled within few hours after extraction from the fruit. The results of the study revealed that under ambient condition, tender palmyra endosperm had a keeping quality (2 days) when packed in LDPE-450 micron film. The keeping quality was (8 days) when packed in $\mathrm{HM}$ 40 micron film under refrigerated condition.

\section{REFERENCES}

Anonymous (1999). All India Co-ordinated Research Improvement programme on palms. Agriculture College and Research Institute, Tamil Nadu Agricultural University, Killikulam, TN and Central Plantation Crops Research Institute (ICAR), Kasaragod.

Bhardwaj, R.L. and Nandal, U. (2014). Effect of Storage Temperature on Physico-Chemical and Sensory Evaluation of Kinnow Mandarin Juice Blends. J Food Process Technol. 5:361.

Catherine Reddy (2013). The Earth of India: All about Nungu, Ice Apple or Taal. http://theindianvegan. blogspot.in/2013/01/all-about-nungu-ice-apple-ortaal.html

Dawn C.P. Ambrose, Annamalai, S.J.K and Ravindra Naik. (2015). Effect of packaging in extending shelf life of curry leaves. Journal of Applied Horticulture 17 (2): 165-168

Elisa Julianti, Ridwansyah, Era Yusraini and Ismed Suhaidi (2012). Effect of Modified Atmosphere Packaging on Postharvest Quality of Rambutan cv. Binjai. Journal of Food Science and Engineering. 2:111-117.

Kishore, K., Pathak, K. A., Shukla, R., and Bharali, R. (2011). Effect of storage temperature on physicochemical and sensory attributes of purple passion fruit (Passiflora edulis Sims). Journal of Food Science and Technology, 48(4), 484-488.

Kudachikar, V. B., Kulkarni, S. G., and Prakash, M. N. K. (2011). Effect of modified atmosphere packaging on quality and shelf life of "Robusta" banana (Musa sp.) stored at low temperature. Journal of Food Science and Technology 48(3): 319-324.

Lee, J.S. and Chandra, D. (2018). Effects of different 
Ambrose D.C.P. / J. Appl. \& Nat. Sci. 10 (2): 705 - 709 (2018)

packaging materials and methods on the physical, biochemical and sensory qualities of lettuce. $J$ Food Sci Technol https://doi.org/10.1007/s13197-0183081-6

Martens, H. and Martens, M., (2001). Multivariate analysis of quality: an introduction, First ed. John Wiley and Sons, Chichester.

Ramya Venkateshwaran (2014). 4 amazing benefits of Palm fruit. http://www.wildturmeric.net/2014/12/4amazing-health-benefits-of-palm-fruit-nungu-tadgolamunjal-fruit.html

Sankaralingam, A.,Hemalatha, G. and Mohamed Ali, A. (1999). A treatise on palmyrah. AICRP on palms report, AC and RI, Tamil Nadu Agricultural Universi- ty, Killikulam,TN, India.

Siddiqui, S., Sharma, R.K. and Gupta, O.P. (1991). Physiological and Quality Response of Guava Fruits to Posture during Storage. HORTSCIENCE 26 (10):1295-1297.

Sohany, M., Sarker, M.K.U. and Mahomud, M.S. (2016) Physiological Changes in Red Onion Bulbs at Different Storage Temperature. World Journal of Engineering and Technology 4: 261-266.

Vijayakumari, P., Vengaiaha, P.C., Kiranmayi, P. (2015). Qualitative phytochemical screening GC-MS Analysis of Antibacterial activity of palmyra fruit pulp. International Journal of Biological and Pharmaceutical Sciences 6(2): 430-435. 